\title{
Energy diagnosis of university buildings: Renewable Energy Institute from UNAM
}

\author{
Oscar González ${ }^{1}$, Miguel Morales ${ }^{1}$, Carla Seefoó ${ }^{1}$, David Morillón ${ }^{2}$, Hugo Valdés ${ }^{3}$ \\ Instituto de Energías Renovables ${ }^{1}$, Instituto de Ingeniería². Universidad Nacional Autónoma de México, \\ México. \\ Centro de Innovación en Ingeniería Aplicada, Universidad Católica del Maule, Chile \\ E-mail: hvaldes@ucm.cl, damg@pumas.ii.unam.mx
}

\begin{abstract}
An energy diagnosis is a tool used to seek the improvement of energy saving measures, environmental conservation and energy efficiency, making relevant its implementation in any kind of buildings. For this article, an energy diagnosis of third level was carried out in buildings of the Instituto de Energías Renovables (IER) from Universidad Nacional Autónoma de México (UNAM) through survey and census of the 36 buildings in the IER, in order to characterize current patterns of energy consumption and demand, and generating specific strategies towards savings and energy efficiency, such as indicators and corrective proposals within and non-financial investment.
\end{abstract}

Keywords: Energy diagnosis, energy efficiency, UNAM, IER, energy consumption and demand.

\section{Introduction}

Currently, renewable energy sources have become very popular due to their advantages in fossil fuel savings and the low or zero emissions of pollutants to the environment during power generation, but these sources still do not meet the energy needs, although they have been decisive in the solution of many energy problems, like in the case of rural electrification and water supply [13]. Thus, the so-called conventional energy sources, based on hydrocarbons or combustible fuels, it remains that the main energy source for both the residential and the productive sector [4]. Therefore, since it cannot be done without these types of energy carriers, it is necessary to strengthen saving measures and rational use of these energy potentials [1].

However, saving and rational use of all energy forms will inevitable presupposes the application and control of a specific and detailed program for that purpose, which is designed from technically based methods or procedures, to identify, regardless of the place it was administered, the efficiency and accountability with which any energy type is used, mainly electricity. For this purpose, a set of elements that allows the performing and evaluating the energy diagnosis are provided [5-7].

An energy diagnosis (DEN) is a tool that analyzes, measures, and evaluates in a systematic and objective way the main energy consuming equipment, systems and processes. Offering a possibility of improvement, modernization and savings thereof, which can lead to greater energy efficiency [810].

With which, it allows to improve the conditions of the environment and the production in which it is wrapped, being able to overcome the current conditions of production and individuals' performance [11]. Normally the realization of an energy diagnosis, made by professionals in this field, lead to reduce production costs without negatively affecting the quality and quantity of it.

Therefore, according to the CONUEE [12], the main objectives of an energy diagnosis are: to establish energy saving goals, to design and apply integral systems for saving energy, evaluate energy saving measures technically and economically and decrease energy consumption, without negatively affecting production levels and conditions.

Although the energy diagnoses are classified according to the depth and the detail when performed, which distinguishes three categories: 
- Level one or basic: it is carried out by visual examination, with which energy consuming equipment is recognized and reviewed, to generate an idea of potential savings, which can go directed to the modification of the habits of operation, correction of waste or incorporation of more efficient technologies. Although not making measurements, the energy saving potentials are merely estimated, thus the savings may or may not be achieved. Its main advantage is to give, at an economic cost, a general idea about the existence of possible energy savings.

- Level two or fundamental: it provides information on energy consumption, whether electric or thermal, by functional areas or specific operation processes; it is most useful to know the potential savings of the facility because most the energy consumers are analyzed qualitatively and quantitatively. This level provides data on energy saving and cost reduction, creating goals for achieving greater energy efficiency. To realize this, it is important to have the equipment and instruments necessary for the evaluation of energy parameters.

- Level three: it generates precise and detailed information, for every one of the relevant points of the industrial process diagram or any installation to be evaluated, as well as the energy losses of all the teams involved. The level is characterized by the participation of specialists, use of extensive instrumentation for data acquisition and engineering studies involved and the actions proposed to achieve energy savings are the product of the reengineering process. The cost is much greater in the second level.

Despite the existence of this classification, the diagnosis energy level is not strict, because in many cases a study can be applied to a single part or stage of the process or installation; creating intermediate levels, that covers certain objectives and scope for a specific area of the process or installation.

\subsection{Background}

Located in the municipality of Temixco, Morelos, the IER is the result of the teaching, research and dissemination activities performed institutionally since 1979 and the transformation of the Energy Research Center (CIE) into an Institute in 2013.

Previously, a DEN had been made in 2006 and then the CIE, which had $12223 \mathrm{~m}^{2}$ distributed within 13 buildings located in a total approximately area of $32581 \mathrm{~m}^{2}$. According to this diagnosis, the activities performed in this institution, electricity was required as the main energy source, in addition to small amounts of LP gas and diesel, the latter to operate the emergency power plant, which was used sporadically when there were power cuts in the area [13]. The activities of this institution have not fundamentally changed in its evolution from center to institute, however it has had a considerable growth. Currently it has $14700 \mathrm{~m}^{2}$ distributed between 36 buildings (Figure 1).

a)
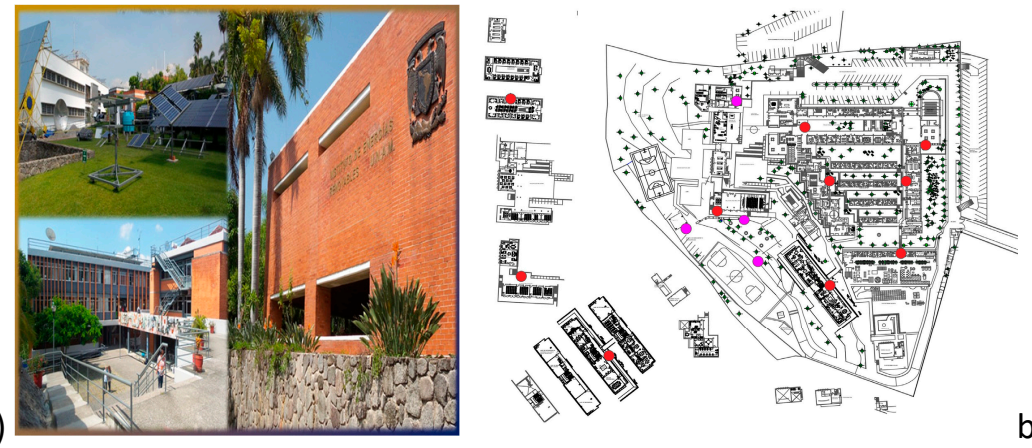

Figure 1. a) Installations of the Renewable Energies Institute of the UNAM. b) General layout of the Renewable Energies Institute (2016). Construction area $14700 \mathrm{~m}^{2}$. 
This work aims to characterize the current patterns of energy consumption in the IER in order to establish a starting point to raise specific strategies aimed at saving energy.

\section{Diagnostic Methodology}

The DEN performed was made up of different stages: authorization management, previous diagnoses review, billing analysis, survey, electrical parameters measurement, energy indicators and corrective measures approach. As follows is the breakdown of each step:

1. Permit management in front of IER authorities. In order to have full cooperation of the IER staff and users at the time of requesting data or conducting the survey, permission and support was requested from Management.

2. Review of energy diagnoses previously made to the institution, in this case, the CIE energy conservation program [13].

3. Electric billing analysis of 32 months, from August 2013 to March 2016.

4. Electrical parameters measurements. Through the use of a DM-III Multitest network analyzer, voltage values, current, consumption, etc. was obtained. The equipment was connected to the IER substation for one week (from Monday to Friday).

5. Survey. It was made for the entire Institute, dividing it into 36 different areas in order to simplify the process of carrying out this step. According to the activities types performed in the IER, interest categories were established for the diagnosis, for each one, a different filing format was designed with electrical parameters of the equipment were sought: computation, air conditioning, laboratory equipment, lighting, workshop, water coolers, fans, miscellaneous and pumps. In each format information was collected about the electrical parameters of each equipment (power, voltage, current), in addition to the time of daily use and the days per week of use. With this information obtained from the formats, an estimation was made of the installed demand, daily and weekly consumption.

6. Energy indicators. According to the ISO 5000-1, Electricity Consumption Indicators (ICEE) were established to qualify the performance of IER buildings; the indexes selected to qualify the institution were: surface ICEE or built per $\mathrm{m}^{2}\left(\mathrm{kWh} / \mathrm{m}^{2}\right)$ and personal ICEE or per capita (kWh/person).

7. Approach corrective measures with or without investment. Once the energy consumption patterns were characterized and the starting point established, various corrective measures were proposed.

\section{Results and Analyze}

\subsection{Electricity Billing}

The Renewable Energy Institute is supplied with electricity by the Federal Electricity Commission CFE, through a contract established for the H-M tariff, which applies to energy services intended for any use, supplying in medium voltage, for which a demand of $100 \mathrm{~kW}$ or more is required. In addition, the CFE makes a distinction of the charges depending on the area in which it is located within Mexican territory. Based on the receipts issued by the CFE for the IER, from August 2013 to March 2016, electricity demand contracted is $130 \mathrm{~kW}$ and corresponds to the central region of the country. Furthermore, there are bonuses for the power factor, which is, for all the revised months. 
Figure 2, it can be observed that the consumption behavior of electrical energy (in kWh) and the potential demand (in kW) for the indicated months. A growing trend can be observed over time, corresponding to the growth that the institute has had in recent years. Also, there are periods where the consumption and demand are lower, which are in the months of June-July and DecemberJanuary. These two periods for holidays for teachers, therefore, the facilities occupants decrease considerably, which is reflected in these consumptions and demands.

If the month of September 2013 is compared to the same month but of 2015, an increase of $21 \%$ in the energy consumed and $29 \%$ in the demand for power was observed. These increases are related to the implementation of the building 3.1 at the end of 2014, which consists of laboratories with specialized equipment for different areas, which consume a lot of energy. If the month of January 2016 is compared to the same month but of the year 2003 [13], there is an increase in consumption in this period of more than $200 \%$, while the demand of power increases by more than $500 \%$.

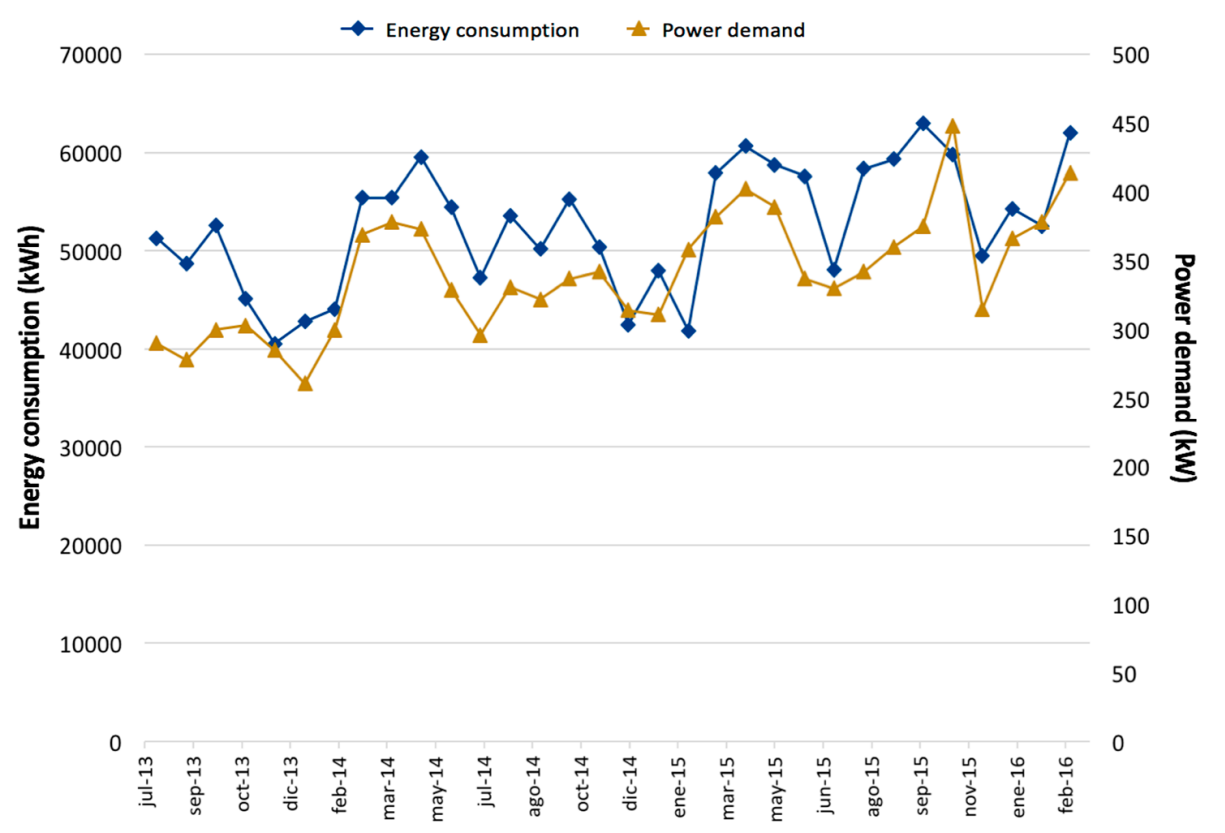

Figure 2. Energy consumption (kWh) and the demand (kW) for the period from August 2013 to March 2016.

These changes in consumption and demand are reflected in the energy and demand charges. Figure 3, one can see the behavior of these concepts throughout the same period. It is noted that the energy charges have been decreasing throughout the period, while the demand charges have increased. This decrease in payment for energy is due to the incorporation of photovoltaic arrays in the institute, which, in achieve maximum power supply to $21 \%$ of the energy consumed by the institute. 


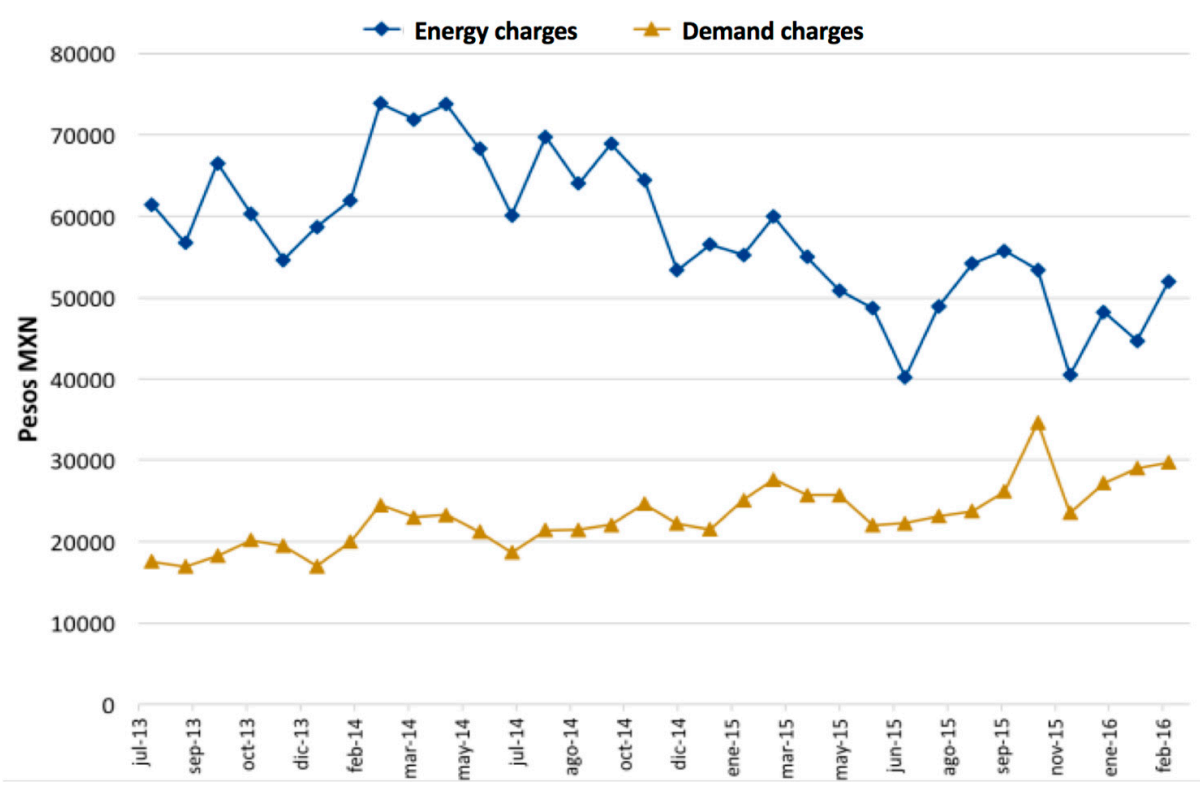

Figure 3. Energy and demand charges in Mexican pesos for the period from August 2013 to March 2016.

\subsection{Electrical parameters measurement}

Figure 4, the instantaneous load profile of IER is shown, it is noted that the demand profile from Monday to Friday is similar, the demand begins to increase at 8:00 h, the time in which work begins in the Institute facilities, while the maximum demand peaks are between 13:00 and 17:00 $\mathrm{h}$. The average maximum registered demand is $102.16 \mathrm{~kW}$. The minimum demand is between 6:00$7: 00 \mathrm{~h}$ during the week and the weekends, the minimum registered value is located between 25 and $75.95 \mathrm{~kW}$.

Comparing the data from 2006, where the average maximum demand was $90 \mathrm{~kW}$, while the minimum demand was around $30 \mathrm{~kW}$ [13]. Demand has grown $16 \%$ in the last 10 years.

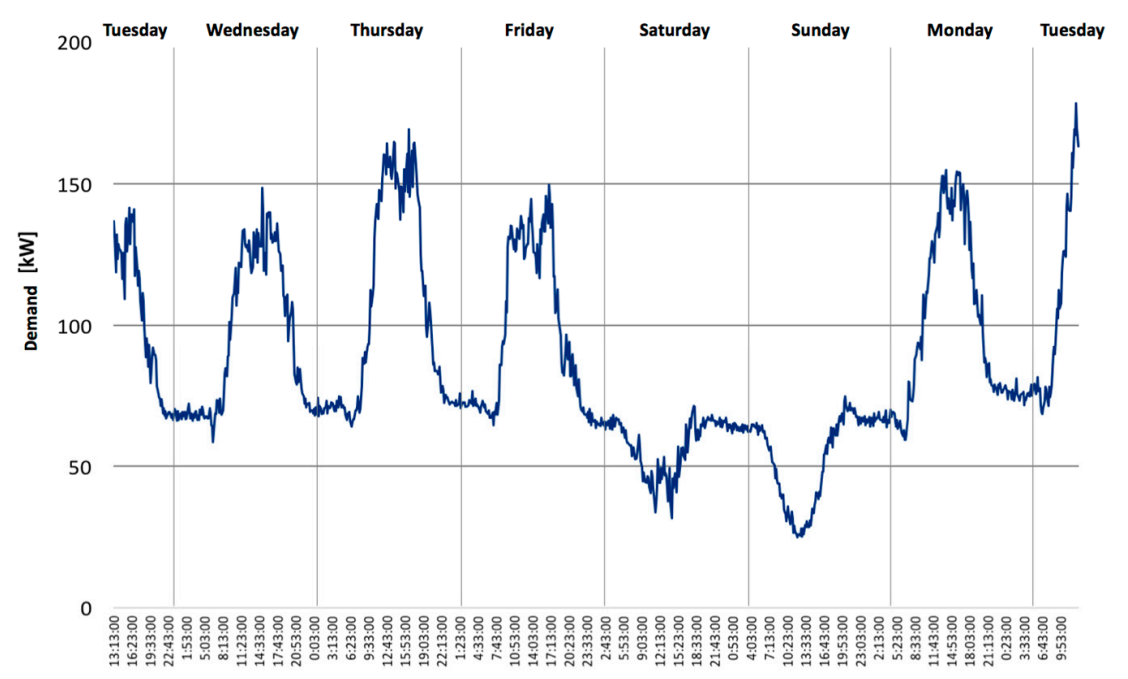

Figure 4. Instantaneous charge profile of the IER during the week 04/26/16 to 05/03/2016. 
The current profile is shown for each phase in Figure 5, as seen, the highest demand is between Monday and Friday and with the instant load profile, this increase starts at 8:00h and maintains a high demand rhythm until approximately 21:00h during the workweek. Meanwhile during the weekends, the demand is minimum.

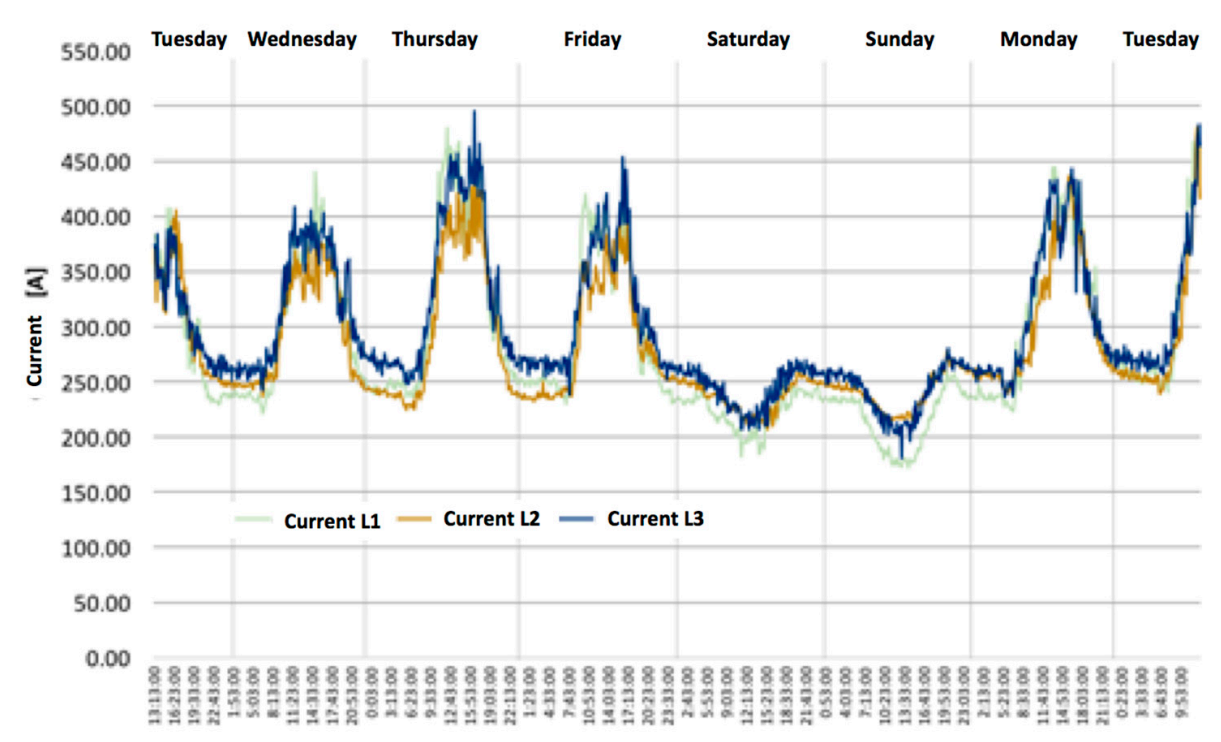

Figure 5. Current profile of the IER for the 3 phases during the week $04 / 26 / 16$ to $05 / 03 / 2016$.

\subsection{Results of the IER-UNAM survey}

A total of 1096 luminaires distributed throughout the institute were counted, representing an installed power of approximately $117.20 \mathrm{~kW}$. In the computer part, there are 411 computer equipment, computers, screens, printers, cannons, etc., which is $103.2 \mathrm{~kW}$ of power. 52 air conditioning equipment of different capacities, which uses $240.60 \mathrm{~kW}$. In Table 1, the daily consumption, weekly consumption and potential demand can be observed for 9 categories in which the survey was divided.

Table 1. Daily and monthly energy and installed demand for the different DEN-IER categories.

\begin{tabular}{l|c|c|c}
\hline Categories & $\begin{array}{c}\text { Daily energy } \\
\text { (kWh) }\end{array}$ & $\begin{array}{c}\text { Monthly energy } \\
\text { (kWh) }\end{array}$ & $\begin{array}{c}\text { Installed demand } \\
\text { (kW) }\end{array}$ \\
\hline Air conditioning & 839.20 & 4884.04 & 240.67 \\
Pump & 60.03 & 327.51 & 17.29 \\
Computers & 688.28 & 3758.93 & 107.91 \\
Chillers (water) & 187.26 & 1007.59 & 18.51 \\
Laboratory equipments & 694.99 & 1929.09 & 116.46 \\
Miscellaneous & 398.90 & 2336.45 & 64.55 \\
Garage & 23.68 & 71.03 & 23.68 \\
Fans & 11.23 & 52.40 & 2.94 \\
Lighting & 851.94 & 4202.60 & 117.17 \\
\hline
\end{tabular}


By scaling these results to one month, which is the time in which the electricity is billed, in Figure 6 the percentage that represents each item in the total energy consumed by the Institute can be seen.

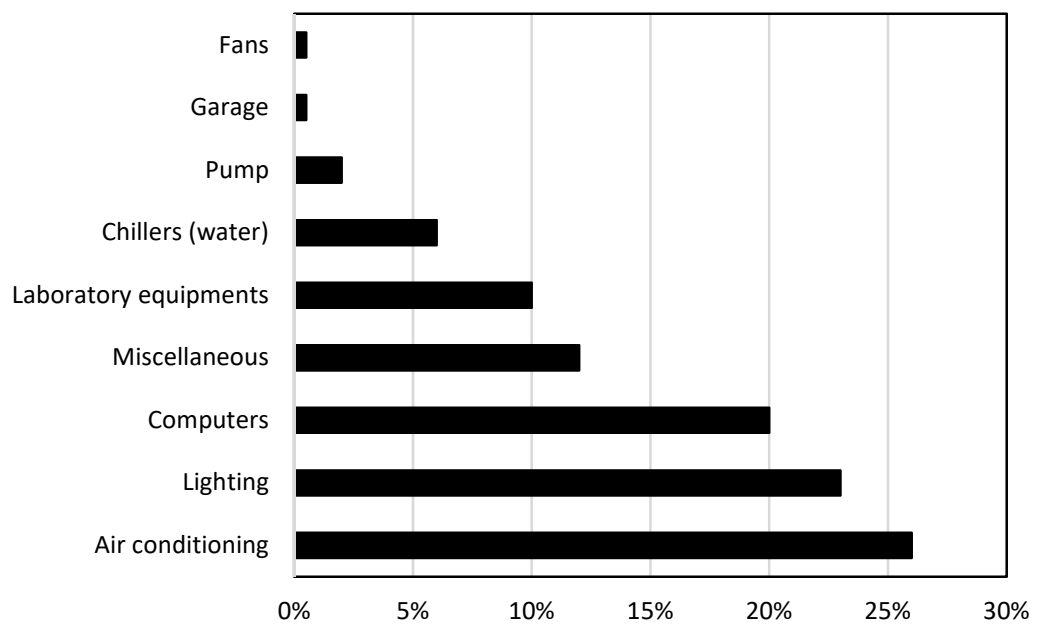

Figure 6. Percentage of monthly equipment consumption.

It is noteworthy that air conditioning and lighting have the highest percentage use, therefore actions must be taken to reduce these percentages.

Making the separation by buildings' consumption, one can see which of those have the greater consumption with respects to others. A separation of the different institute buildings is made according to what the same main activity is, thus obtaining, 12 different categories: exteriors, laboratories, cubicles from A to E, administrative, mechanical workshop, classrooms, library, and cafeteria. Figure 7, the distribution of the consumption percentage by area can be seen.

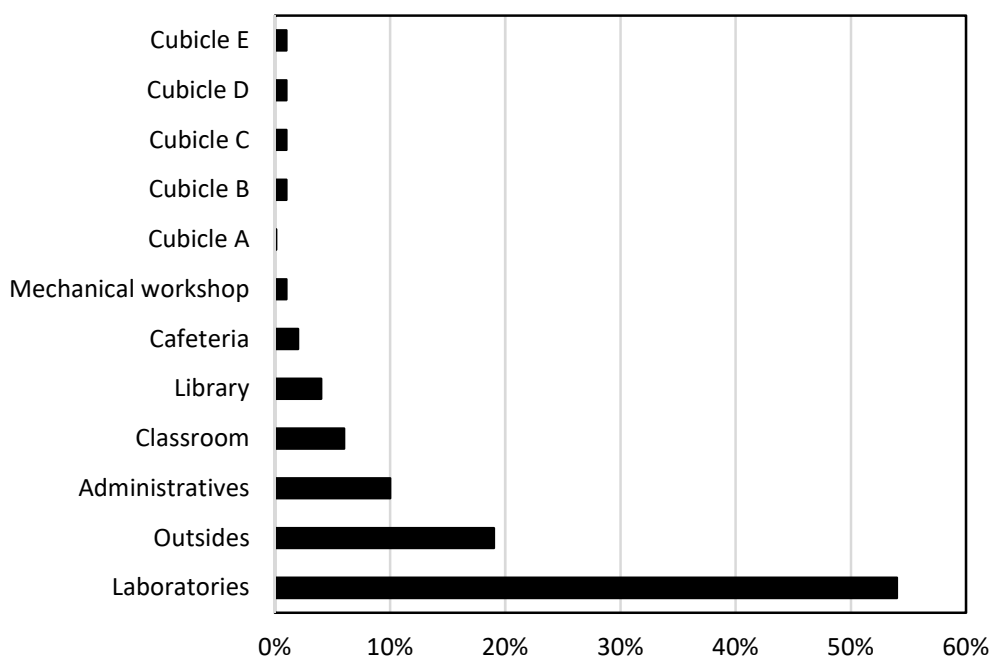

Figure 7. Consumption percentage by area. 
More than half the energy goes to the laboratories, which is consistent with the research function of the institute. The exterior part, which represents a higher equal part, corresponds to all the lighting available at nighttime. Figure 8 , a breakdown of laboratories is shown to find out which of those that consume the most and direct the proposals for saving and efficient use.

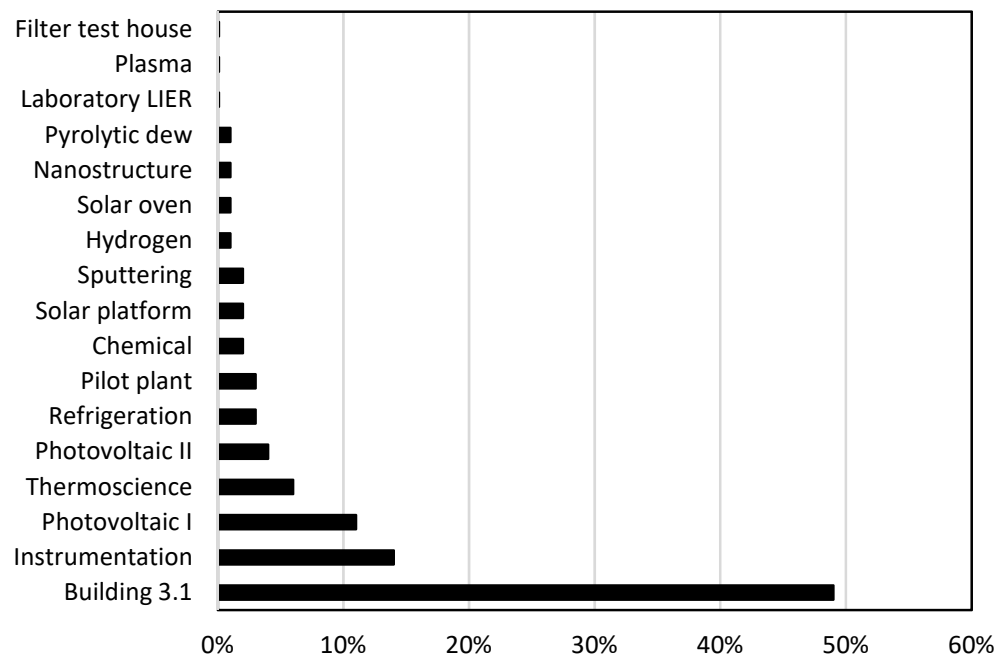

Figure 8. Breakdown of the laboratories monthly consumption percentage.

From Figure 8 , it can see that most of energy consumption goes to Building 3.1, which concentrates a large amount of laboratories specialized in renewable energy research and innovation. This new building is fully equipped with air conditioning systems, which is reflected in its higher consumption. Furthermore, most of the equipment that counts inside manage experiments throughout the day for several days a week. The rest of the laboratories were built with a philosophy of not using the air conditioning systems expect those in which a controlled temperature environment is required, as in the case of the instrumentation and photovoltaic laboratories.

\subsection{Indicators}

The energy indicators serve as a basis to determine the most characteristic data and are more susceptible to changes; such indicators also presents a good tool for comparing energy behavior between commercial buildings and similar services and shows clearer and more precise results. In this work, this type of indicators in distinct commercial buildings of the country is analyzed. A general management is presented in the following.

The selection of two indicators was made, as stipulated in ISO 5000-1, which represents essential information of the building's energy performance. These indicators allows the comparison between similar buildings and provides information on how efficient or not the electricity consumption is in a specific building.

The more precise way of determining the consumption level of a building's electric energy is calculated by $\mathrm{kWh} / \mathrm{m}^{2}$ and $\mathrm{kWh} /$ person monthly or yearly, that is, the annual energy use by area and users of the building. This measurement is commonly used to evaluate and compare energy efficiency of buildings [14]. After analyzing each of the surveys, Indicators of Electric Power Consumption (ICEE) was calculated in the following manner: 
Surface ICEE: Monthly building consumption $(\mathrm{kWh}) /$ constructed area $\left(\mathrm{m}^{2}\right)$. Personal ICEE: Monthly building consumption (kWh)/building use.

Table 2. ICEE for buildings of IER-UNAM.

\begin{tabular}{|c|c|c|}
\hline Buildings of IER-UNAM & Surface ICEE & Personal ICEE \\
\hline Administration & 71.87 & 47.23 \\
\hline Library & 280.42 & 470.71 \\
\hline Cafeteria & 136.45 & 52.53 \\
\hline Courts & 11.63 & 58.18 \\
\hline Filters test house & 1.06 & 2.82 \\
\hline Vigilance stand & 652.55 & 469.83 \\
\hline CEMIE & 118.25 & 170.72 \\
\hline Cubicles A & 77.82 & 60.45 \\
\hline Cubicles B & 61.26 & 52.21 \\
\hline Cubicles C & 54.47 & 47.66 \\
\hline Cubicles D & 71.00 & 63.14 \\
\hline Cubicles E & 172.31 & 161.54 \\
\hline Management office & 114.05 & 184.23 \\
\hline Building 3.1 & 1697.43 & 112.19 \\
\hline Outsides & 0.39 & 1205.73 \\
\hline Solar oven & 9.79 & 58.75 \\
\hline Lab. Photovoltaic I & 752.73 & 376.36 \\
\hline Lab. Photovoltaic II & 542.88 & 232.66 \\
\hline Lab. Hydrogen & 64.56 & 69.94 \\
\hline Lab. Instrumentation & 4424.41 & 557.48 \\
\hline Lab. Nanostructures & 52.83 & 66.04 \\
\hline Lab. Metallic oxides & 28.47 & 21.35 \\
\hline Lab. Plasma & 22.80 & 20.90 \\
\hline Lab. Chemical I & 51.79 & 274.47 \\
\hline Lab. Refrigeration and heat pump & 83.53 & 71.60 \\
\hline Lab. Pyrolytic dew & 74.65 & 74.65 \\
\hline Lab. Sputtering & 622.72 & 259.47 \\
\hline Lab. Thermoscience & 941.60 & 1279.64 \\
\hline Lab. LIER & 8.17 & 26.95 \\
\hline Lobby & 46.84 & 312.27 \\
\hline Pilot plant & 1082.61 & 582.94 \\
\hline Solar platform & 7.83 & 262.07 \\
\hline Postgrade & 348.98 & 23.06 \\
\hline STUNAM & 89.93 & 214.03 \\
\hline Garage & 20.70 & 117.26 \\
\hline Tonatiuh & 4.37 & 9.91 \\
\hline AVERAGE & 560.93 & 224.19 \\
\hline
\end{tabular}

Taking into account the most current data given by the Energy Information System (SIE) of the Secretariat of Energy (SENER), for the year 2015, the annual consumption per capital in the country was $2.055 .59 \mathrm{kWh} /$ inhabitant, thus $171.30 \mathrm{kWh} /$ inhabitant monthly from that year [14]; is compared to the average value of $\mathrm{kWh} / \mathrm{inh}$ habitant of the IER, obtained in Table 2, the number is lower by approximately $40 \mathrm{kWh} /$ inhabitant. 
Regarding the indicator of energy consumption per square meter was constructed, it is important to highlight that the IER has several uses within the same facilities, among which: offices, schools, research laboratories and even restaurants: therefore, to use it, one needs to select one of the buildings of the uprising and specify its main use.

\subsection{Proposals}

Having collected the information and analyzed it, a package of proposals that are thought to help the institution's energy and monetary savings and consequently the environmental care was generated; proposing the following:

a) Operational measures to reduce energy consumption from the miscellany item:

- Turn off and unplug equipment that is not in use (for example, coffee makers, printers, fans, charges, microwaves, projectors, etc.)

- Turn off lights and try to make the most of natural light.

- Disconnect water dispensers during the nighttime.

- Activate the "energy save mode" on the devices that allow it.

b) Installation of thermal insulation for buildings with air conditioning.

c) Due to the climate characteristics in Temixco, the use of evaporative coolers or "cooler" instead of air conditioning systems is proposed.

d) A specialized technician performs annual maintenance on each installed equipment. Taking into account the reference to a study by CONUEE that air conditioners that go two or more years without maintenance, consume twice as much energy [12].

e) Replacement of T8 light fixtures with T5 light fixtures, which have a wide range applications such as offices and research institutes, it also has a lifespan of 24,000 hours resulting in 2.7 years and a lighting efficacy up to $104 \mathrm{Im} / \mathrm{W}$ at a temperature of $35^{\circ} \mathrm{C}$, which is adapted to a climatic conditions of the state of Morelos.

f) Replacing lights in sports area with LED Reflectors [15] of 50W, which implies a saving of $95 \%$ of the energy consumed by a single light of the 8 currently installed, which also has a lifespan of more than 50,000 hours which translate into 5.7 years $[16,17]$.

g) Awareness campaigns and the training occupants with good habits, who are considered final user of electric services in the different buildings that make up the IER.

h) The use and promotion of solar air conditioning created by entity investigators.

i) Automated use of primary lighting and air conditioning.

This is how, adding these types of proposals, some which do not necessarily need financial support but rather lots of individual contribution, the goal is to have an energy efficient institute can be achieved.

\section{Conclusions}

As the Renewable Energy Institute has grown throughout history, its energy consumption as increased at par and despite this, their consumption patterns continue, although higher are still very similar in charge and current drive; and showing that the air conditioning, computing and laboratory devices or equipment that demand and consume the most. This led us to generate strategies and proposals that help the IER to achieve greater energy efficiency, which requires in full the support of each person who studies and works in the entity, while some also require economic stimulus for its implementation. 


\section{Acknowledgements}

This work was based on a diagnosis made by students of the Engineering Bachelor in Renewable Energy (LIER) of the UNAM. We would also like to thank the academics, administrative, unionized staff and students in general for the IER-UNAM. Thanks to The Pacific Alliance for the Alianza Pacifico Scholarship granted to Dr. Hugo Valdés of the Universidad Catolica del Maule, who agreed to finance the collaboration on this study together with Dr. David Morillon at the UNAM.

\section{References}

[1] Hernández, M.; Labrador, L. Diagnóstico energético. CUBASOLAR, Cuba, 2016, Consulta en línea en: [http://goo.gl/BG7kce]

[2] Lucheroni, C.; Mari, C. Optimal Integration of Intermittent Renewables: A System LCOE Stochastic Approach. Energies, 2018, vol. 11, oㅡ 3, p. 549.

[3] Pascual, J.; Sanchis, P.; Marroyo, L. Implementation and control of a residential electrothermal microgrid based on renewable energies, a hybrid storage system and demand side management. Energies, 2014, vol. 7, no 1, p. 210-237.

[4] Sekoai, P.T.; Yoro, K. O. Biofuel development initiatives in Sub-Saharan Africa: opportunities and challenges. Climate, 2016, vol. 4, no 2, p. 33.

[5] Neymark, J.; Judkoff, R. International Energy Agency Building Energy Simulation Test and Diagnostic Method for Heating, Ventilating, and Air-Conditioning Equipment Models (HVAC BESTEST); Volume 1: Cases E100-E200. National Renewable Energy Lab., Golden, CO.(US), 2002.

[6] Ascione, F.; De Masi, R. F.; de Rossi, F.; Fistola, R.; Sasso, M.; Vanoli, G. P. Analysis and diagnosis of the energy performance of buildings and districts: Methodology, validation and development of Urban Energy Maps. Cities, 2013, vol. 35, p. 270-283.

[7] Geng, Y.; Ji, W.; Lin, B.; Hong, J.; Zhu, Y. Building energy performance diagnosis using energy bills and weather data. Energy and Buildings, 2018, vol. 172, p. 181-191.

[8] Katipamula, S.; Brambley, M. R. Methods for fault detection, diagnostics, and prognostics for building systems -a review, part I. Hvac\&R Research, 2005, vol. 11, no 1, p. 3-25.

[9] Katipamula, S.; Brambley, M. R. Methods for fault detection, diagnostics, and prognostics for building systems-a review, part II. Hvac\&R Research, 2005, vol. 11, no 2, p. 169-187.

[10] Zhao, H.; Magoulès, F. A review on the prediction of building energy consumption. Renewable and Sustainable Energy Reviews, 2012, vol. 16, № 6, p. 3586-3592.

[11] Ahmad, M. W.; Mourshed, M.; Mundow, D.; Sisinni, M.; Rezgui, Y. Building energy metering and environmental monitoring-A state-of-the-art review and directions for future research. Energy and Buildings, 2016, vol. 120, p. 85-102.

[12] CONUEE. Comisión Nacional para el Uso Eficiente de la Energía. ACCIONES Y PROGRAMAS. 2016. Consulta en línea [http://goo.gl/W4mS89]

[13] Dorantes, R.; González, B. Programa de conservación de energía en el CIE. Centro de Investigación en Energía de la UNAM. 2006. México.

[14] SENER, AIE (2011). Indicadores de Eficiencia Energética en México: 5 sectores, 5 retos. México. Consulta en línea en: [http://goo.gl/F9a8r8]

[15] Ecolight, 2016. Catálogo de productos. México. Consulta en línea en: [http://goo.gl/SAbclU]

[16] OSRAM, 2016. Lumilux T8. Consulta línea en: [http://goo.gl/zxa0pE]

[17] Schneider Electric (2008). GUÍA DE DISEÑO DE INSTALACIONES ELÉCTRICAS, CAPÍTULO M. 